\title{
Natural zeolite as environmentally friendly supplementary cementitious material in concrete
}

\author{
E. Vejmelková ${ }^{1}$, T. Kulovaná ${ }^{1}$, M. Keppert ${ }^{1}$, M. Ondráček ${ }^{2}$ \\ \& R. Černý ${ }^{1}$ \\ ${ }^{I}$ Department of Materials Engineering and Chemistry, Faculty of Civil \\ Engineering, Czech Technical University in Prague, Czech Republic \\ ${ }^{2}$ Institute of Technology of Building Materials and Components, Faculty \\ of Civil Engineering, Brno University of Technology, Czech Republic
}

\begin{abstract}
Selected mechanical, thermal, hygric, and durability properties of several concrete mixes containing natural zeolite as partial replacement of Portland cement are studied and compared with reference concrete. Experimental results show that natural zeolite has a potential to replace a part of Portland cement in concrete in the building industry. However, it is shown that although from both environmental and economical points of view it would be desirable to use its highest possible amounts in concrete production, the extent of Portland cement replacement which could be chosen in preparation of concrete mixes has relatively strict limitations. Concrete with the replacement of Portland cement by natural zeolite in the amount of $20 \%$ by mass is found to be the most suitable solution among the analyzed mixes.

Keywords: high performance concrete, natural zeolite, mechanical properties, hygric properties, thermal properties, durability.
\end{abstract}

\section{Introduction}

Supplementary cementitious materials (SCM) are widely used as concrete admixtures which are able to substitute a part of Portland cement dose in fresh concrete mixture. Utilization of SCM is thus accompanied by lower demand of energy needed for Portland clinker calcination which usually results in lower 
production costs and $\mathrm{CO}_{2}$ emissions. Moreover, the application of $\mathrm{SCM}$ can improve properties of hardened concrete, namely strength and durability related parameters. SCM can be divided according to their chemical character (pozzolanic, hydraulic) or origin (natural, wastes, secondary product, primary product).

Zeolites are natural volcanic or synthesized aluminosilicate minerals with typical microporous framework structure. Thanks to their high specific surface, they are widely used mainly in chemical engineering as catalyst support, molecular sieves and sorbents, but their utilization as pozzolans dates back already to ancient times when the mixture of zeolites containing tuff and lime was used as hydraulic binder [1]. Today's research and utilization of zeolites as concrete admixtures is obviously focused on naturally occurring minerals which are exploited in several countries (China, Japan; the most important European producer of natural zeolites is Slovakia) but certain attention has been paid also to recycling of spent zeolite catalysts from petrochemistry [2]. Generally, zeolites - as other pozzolans - are taking part in hydration reactions and contribute to strength of cementitious materials. Poon et al. [3] compared pozzolanic reactivity of several pozzolans and concluded that pozzolanic activity of zeolites lies between silica fume as the highest and coal fly ash as the lowest. Feng et al. [4] compared influence of various pozzolans including natural zeolite on the charge passed of concrete. Ahmadi and Shekarchi [5] observed positive effect of zeolite cement replacement in mortars on compressive strength and resistance to ASR. The positive influence of zeolite on concrete sulfate corrosion was observed as well [6]. Bilim [7] and Sisman and Gezer [8] recommended only moderate $(5 \%)$ cement replacement by natural zeolite.

In this paper, natural zeolite is used as an alternative binder in high performance concrete (HPC), replacing Portland cement in the amount of up to $40 \%$ of mass. Selected mechanical, thermal, hygric, and durability properties of several concrete mixes are studied and compared with reference concrete.

\section{Materials and samples}

The high performance concrete mixtures presented in Table 1 were prepared with Portland cement CEM I $42.5 \mathrm{R}$ (its specific surface area was $341 \mathrm{~m}^{2} \mathrm{~kg}^{-1}$ ) as

Table 1: Composition of studied concretes.

\begin{tabular}{|c|c|c|c|c|}
\hline \multirow{2}{*}{ Component } & \multicolumn{4}{|c|}{ Composition $\left[\mathrm{kgm}^{-3}\right]$} \\
\cline { 2 - 5 } & CZ-ref & CZ-10 & CZ-20 & CZ-40 \\
\hline CEM I 42.5 R & 484 & 436 & 387 & 305 \\
\hline natural zeolites & - & $48(10 \%)$ & $97(20 \%)$ & $179(40 \%)$ \\
\hline aggregates 0-4 mm & 812 & 812 & 812 & 812 \\
\hline aggregates 8-16 mm & 910 & 910 & 910 & 910 \\
\hline $\begin{array}{c}\text { plasticizer Mapei } \\
\text { Dynamon SX }\end{array}$ & 5.3 & 5.3 & 5.3 & 5.3 \\
\hline water & 172 & 194 & 221 & 244 \\
\hline
\end{tabular}


the main binder. A part of cement (10-40\%) was replaced by natural zeolite (its specific surface area was $\left.589 \mathrm{~m}^{2} \mathrm{~kg}^{-1}\right)$. The chemical composition of cement and natural zeolite is shown in Table 2.

The measurement of material parameters of hardened concrete mixes was done after 28 days of standard curing. It took place in a conditioned laboratory at the temperature of $22 \pm 1^{\circ} \mathrm{C}$ and $25-30 \%$ relative humidity.

Table 2: $\quad$ Chemical composition of cement and zeolite.

\begin{tabular}{|c|c|c|}
\hline \multirow{2}{*}{ Component } & \multicolumn{2}{|c|}{ Amount [\%] } \\
\cline { 2 - 3 } & Cement & Zeolite \\
\hline $\mathrm{SiO}_{2}$ & 21.89 & 68.15 \\
\hline $\mathrm{Al}_{2} \mathrm{O}_{3}$ & 5.6 & 12.3 \\
\hline $\mathrm{Fe}_{2} \mathrm{O}_{3}$ & 3.75 & 1.3 \\
\hline $\mathrm{CaO}$ & 62.33 & 2.63 \\
\hline $\mathrm{MgO}$ & 1.04 & 0.9 \\
\hline $\mathrm{K}_{2} \mathrm{O}$ & 0.92 & 2.8 \\
\hline $\mathrm{Na}_{2} \mathrm{O}$ & 0.11 & 0.75 \\
\hline $\mathrm{TiO}_{2}$ & 0.3 & 0.2 \\
\hline $\mathrm{P}_{2} \mathrm{O}_{5}$ & 0.17 & - \\
\hline $\mathrm{SO}_{3}$ & 2.88 & - \\
\hline
\end{tabular}

\section{Experimental methods}

\subsection{Basic physical properties}

As fundamental physical material characteristics, bulk density $\rho_{b}\left[\mathrm{kgm}^{-3}\right]$, open porosity $\Psi[\%]$ and matrix density $\rho_{\text {mat }}\left[\mathrm{kgm}^{-3}\right]$ were determined by the water vacuum saturation method [9]. Each sample was dried in a drier to remove majority of the physically bound water. After that the samples were placed into the desiccator with deaired water. During three hours air was evacuated with vacuum pump from the desiccator. The sample was then kept under water for not less than 24 hours.

\subsection{Pore structure}

Characterization of pore structure was performed by mercury intrusion porosimetry. The experiments were carried out using the instruments PASCAL 140 and 440 (Thermo Scientific). The range of applied pressure corresponds to pore diameter from $3 \mathrm{~nm}$ to $1000 \mu \mathrm{m}$. Since the size of the specimens is restricted to the volume of approximately $1 \mathrm{~cm}^{3}$ and the studied materials contained some aggregates about the same size, the porosimetry measurements were performed on samples without coarse aggregates. 


\subsection{Mechanical properties}

The measurement of compressive strength was done by the hydraulic testing device VEB WPM Leipzig having a stiff loading frame with the capacity of 3000 $\mathrm{kN}$. The tests were performed according to ČSN EN 12390-3 [10] after 28 days of standard curing. The bending strength was determined using the procedure described in ČSN EN 12390-5 [11] after 28 days of standard curing as well. The measurement was done on the $150 \mathrm{~mm}$ cubes (compressive strength) and on the samples with the dimensions of $100 \times 100 \times 400 \mathrm{~mm}$ (bending strength).

\subsection{Resistance against de-icing salts}

The resistance of studied composites against de-icing salts was measured according to ČSN 731326/Z1:1984 [12]. The tested specimens are saturated by water and put into a bath with $3 \% \mathrm{NaCl}$ solution. Then, freeze-thaw cycles are applied. In one cycle the tested specimen is cooled at first in an automatic conditioning device from $20^{\circ} \mathrm{C}$ to $-15^{\circ} \mathrm{C}$ during 45 minutes, then it is left at $15^{\circ} \mathrm{C}$ for 15 minutes, subsequently heated to $20^{\circ} \mathrm{C}$ during 45 minutes and left 15 minutes at that temperature. After every 25 cycles the specimens are removed from the bath, their mass loss due to spalling of particles on the surface determined, the $\mathrm{NaCl}$ solution is replaced and specimens put into the bath again. The test is finished either after the prescribed number of cycles or after the mass loss exceeds $1000 \mathrm{gm}^{-2}$.

\subsection{Water transport properties}

The liquid water transport was characterized by the water absorption coefficient $A\left[\mathrm{~kg} \mathrm{~m}^{-2} \mathrm{~s}^{-1 / 2}\right]$ and apparent moisture diffusivity $\kappa\left[\mathrm{m}^{2} \mathrm{~s}^{-1}\right]$. The specimen was water- and vapor-proof insulated on four lateral sides and the face side was immersed $1 \mathrm{~mm}$ under the water level. Constant water level in the tank was achieved by a Mariotte bottle with two capillary tubes [13]. The measurement was done on the samples with the dimensions of $100 \times 100 \times 20 \mathrm{~mm}$.

\subsection{Water vapor transport properties}

The dry cup method was employed in the measurements of water vapor transport parameters [9]. The water vapor diffusion permeability $\delta$ [s], water vapor diffusion coefficient $D\left[\mathrm{~m}^{2} \mathrm{~s}^{-1}\right]$ and water vapor diffusion resistance factor $\mu[-]$ were determined. The measurement was done on the samples with the dimensions of $150 \times 150 \times 20 \mathrm{~mm}$.

\subsection{Sorption isotherms}

Water adsorption and desorption isotherms were determined using the desiccators method [9]. The measurement was done on the samples with the dimensions of $40 \times 40 \times 10 \mathrm{~mm}$. 


\subsection{Thermal properties}

Thermal conductivity $\lambda\left[\mathrm{W} \mathrm{m}^{-1} \mathrm{~K}^{-1}\right]$ and specific heat capacity $c\left[\mathrm{~J} \mathrm{~kg}^{-1} \mathrm{~K}^{-1}\right]$, were measured using the commercial device ISOMET 2104 (Applied Precision, Ltd.). The measurement is based on analysis of the temperature response of the analyzed material to heat flow impulses. The heat flow is induced by electrical heating using a resistor heater having a direct thermal contact with the surface of the sample. The measurement was done on the samples with the dimensions of $70 \times 70 \times 70 \mathrm{~mm}$.

\section{Experimental results and discussion}

\subsection{Basic physical properties}

The basic physical parameters of studied materials are shown in Table 3 . The bulk density of the analyzed concretes decreased with the increasing amount of natural zeolite. The open porosity increased in the corresponding way. The values of matrix density were almost the same (within a 1\% limit) for all studied concretes.

Table 3: $\quad$ Basic physical properties of studied concretes.

\begin{tabular}{|c|c|c|c|}
\hline \multirow{2}{*}{ Material } & $\rho_{\mathrm{b}}$ & $\rho_{\text {mat }}$ & $\psi$ \\
\cline { 2 - 4 } & {$\left[\mathrm{kg} \mathrm{m}^{-3}\right]$} & {$\left[\mathrm{kg} \mathrm{m}^{-3}\right]$} & {$[\%]$} \\
\hline CZ-ref & 2244 & 2590 & 13.4 \\
\hline CZ10 & 2194 & 2601 & 15.7 \\
\hline CZ20 & 2132 & 2601 & 18.0 \\
\hline CZ40 & 2036 & 2623 & 22.4 \\
\hline
\end{tabular}

\subsection{Pore structure}

The MIP curves of zeolite containing materials featured very high slopes in pore diameter region of a few nanometers (Figure 1) while the MIP curve of the control sample CZ-ref was flat in this area. It can be attributed to the presence of non-reacted residuals of zeolite particles which preserved its natural framework structure with a high amount of very small pores. Fortunately the small pores do not influence the durability properties of materials. The increase of capillary pores volume due to zeolite admixing was found to be very low. 


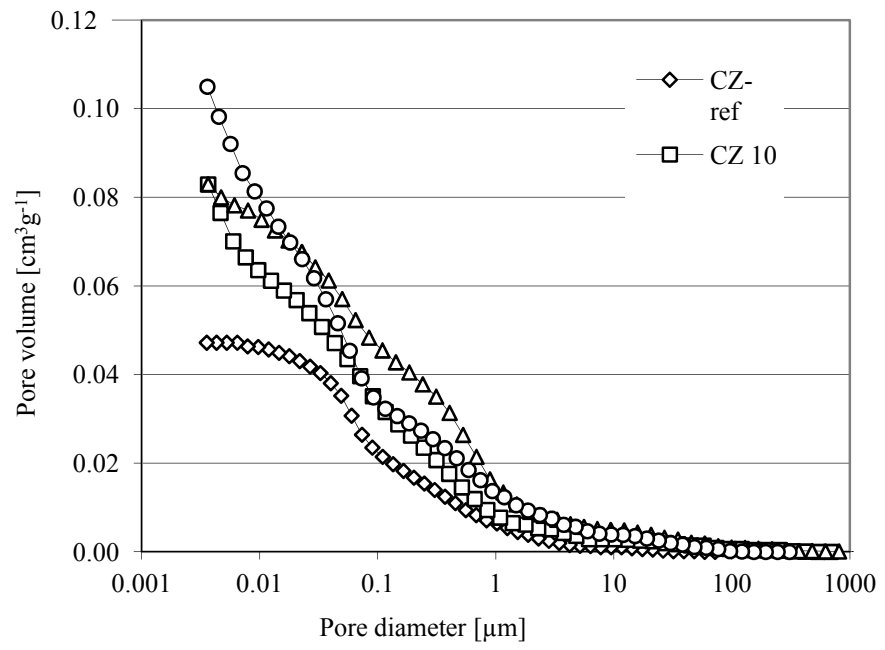

Figure 1: $\quad$ Cumulative pore size distribution of studied concretes.

\subsection{Mechanical properties}

Table 4 shows that the compressive strength of studied concretes decreased significantly with the increasing amount of natural zeolite used as the replacement of Portland cement.

Table 4: $\quad$ Mechanical properties of studied concretes.

\begin{tabular}{|c|c|c|c|}
\hline \multirow{2}{*}{ Material } & \multicolumn{3}{|c|}{ Compressive strength [MPa] } \\
\cline { 2 - 4 } & 7 days & 28 days & 360 days \\
\hline CZ-ref & 51.0 & 71.9 & 77.7 \\
\hline CZ-10 & 48.9 & 63.7 & 64.1 \\
\hline CZ-20 & 33.4 & 54.2 & 58.4 \\
\hline CZ-40 & 18.8 & 36.4 & 42.8 \\
\hline
\end{tabular}

The 7-day strengths were similar for the reference concrete and CZ-10. For higher amounts of natural zeolites in the mix the compressive strength was significantly lower which was an expected outcome, taking into account the pozzolanic properties of zeolites. The values of compressive strength after 28 days showed that up to the $20 \%$ replacement level the concretes still maintained their high performance character but for CZ-40 a 50\% decrease was observed which was not satisfactory. The differences in compressive strength after 360 days were similar to 28 days. 


\subsection{Resistance against de-icing salts}

The resistance against de-icing salts (Figure 2) was very bad for mixes with higher Portland cement replacement level. For CZ-20 and CZ-40 the loss of mass exceeded the standard limit of $1000 \mathrm{gm}^{-2}$ already after 25 cycles, for CZ-10 it was after 50 cycles. Only the reference CZ-ref met the requirements of the standard.

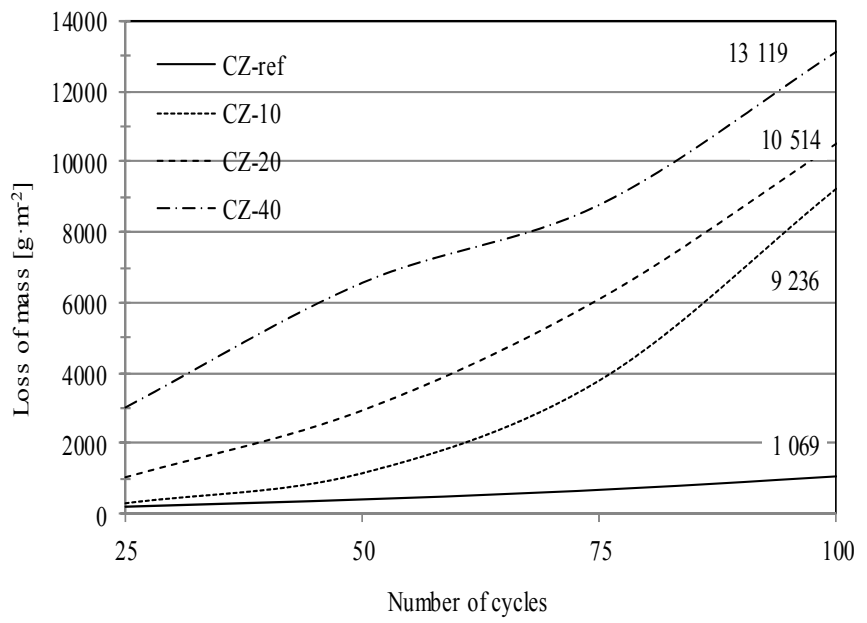

Figure 2: Loss of mass of studied concretes due to the de-icing salts action.

\subsection{Water transport properties}

The results of water sorptivity measurements are presented in Table 5.

Table 5: $\quad$ Water transport properties of studied concretes.

\begin{tabular}{|c|c|c|}
\hline \multirow{2}{*}{ Material } & $\mathrm{A}$ & $\kappa$ \\
\cline { 2 - 3 } & {$\left[\mathrm{kg} \mathrm{m}^{-2} \mathrm{~s}^{-1 / 2}\right]$} & {$\left[\mathrm{m}^{2} \mathrm{~s}^{-1}\right]$} \\
\hline CZ-ref & 0.0086 & $4.275 \mathrm{E}-09$ \\
\hline CZ-10 & 0.0096 & $3.919 \mathrm{E}-09$ \\
\hline CZ-20 & 0.0153 & $7.421 \mathrm{E}-09$ \\
\hline CZ-40 & 0.0317 & $2.082 \mathrm{E}-08$ \\
\hline
\end{tabular}

We can see that the increase of open porosity with increasing amount of natural zeolite led to a significant enhancement of liquid water transport. The apparent moisture diffusivity of CZ-40 was about five times higher than reference concrete. Similarly as with the compressive strength, 20\% replacement level could be considered a reasonable limit, as for the liquid water transport parameters. 
Table 6: Water vapor transport properties of studied concretes.

\begin{tabular}{|c|c|c|c|c|c|c|}
\hline \multirow{2}{*}{ HPC } & \multicolumn{3}{|c|}{$5 / 50 \%$} & \multicolumn{3}{c|}{$97 / 50 \%$} \\
\cline { 2 - 7 } & $\delta$ & $\mathrm{D}$ & $\mu$ & $\delta$ & $\mathrm{D}$ & $\mu$ \\
\cline { 2 - 7 } & {$[\mathrm{s}]$} & {$\left[\mathrm{m}^{2} \mathrm{~s}^{-1}\right]$} & {$[-]$} & {$[\mathrm{s}]$} & {$\left[\mathrm{m}^{2} \mathrm{~s}^{-1}\right]$} & {$[-]$} \\
\hline CZ-ref & $1.58 \mathrm{E}-12$ & $2.18 \mathrm{E}-07$ & 106.69 & $1.92 \mathrm{E}-12$ & $2.64 \mathrm{E}-07$ & 89.75 \\
\hline CZ-10 & $2.05 \mathrm{E}-12$ & $2.82 \mathrm{E}-07$ & 81.87 & $2.43 \mathrm{E}-12$ & $3.34 \mathrm{E}-07$ & 68.87 \\
\hline CZ-20 & $2.85 \mathrm{E}-12$ & $3.92 \mathrm{E}-07$ & 58.78 & $3.57 \mathrm{E}-12$ & $4.91 \mathrm{E}-07$ & 49.45 \\
\hline CZ-40 & $4.72 \mathrm{E}-12$ & $6.49 \mathrm{E}-07$ & 35.42 & $6.51 \mathrm{E}-12$ & $8.95 \mathrm{E}-07$ & 29.8 \\
\hline
\end{tabular}

\subsection{Water vapor transport properties}

Table 7 shows that the water vapor diffusion coefficient of studied materials increased with increasing amount of natural zeolite in the mix which was in accordance with the open porosity data in Table 3 .

The measured data also revealed that the values of water vapor diffusion coefficient corresponding to the lower values of relative humidity $(5 / 50 \%)$ were always lower than those for higher relative humidity values (97/50 \%). This is related to the partial transport of capillary condensed water in the wet-cup arrangement [14].

Table 7: Thermal properties of studied concretes in dry state

\begin{tabular}{|l|c|c|}
\hline \multirow{2}{*}{$\mathrm{HPC}$} & $\lambda$ & $\mathrm{c}$ \\
\cline { 2 - 3 } & {$\left[\mathrm{Wm}^{-1} \mathrm{~K}^{-1}\right]$} & {$\left[\mathrm{Jkg}^{-1} \mathrm{~K}^{-1}\right]$} \\
\hline CZ-ref & 1.623 & 738 \\
\hline CZ-10 & 1.513 & 732 \\
\hline CZ-20 & 1.397 & 729 \\
\hline CZ-40 & 1.167 & 706 \\
\hline
\end{tabular}

\subsection{Sorption isotherms}

Figure 3 shows the measured adsorption (lower curves) and desorption (upper curves) isotherms.

The differences in adsorption and desorption isotherms were for all studied materials relatively high. This indicated a considerable amount of "bottleneck" pores. The water vapor adsorption capacity increased significantly with the increasing content of zeolite which was related to the high amount of very small pores in CZ-10, CZ-20 and CZ-40 (Figure 1). 


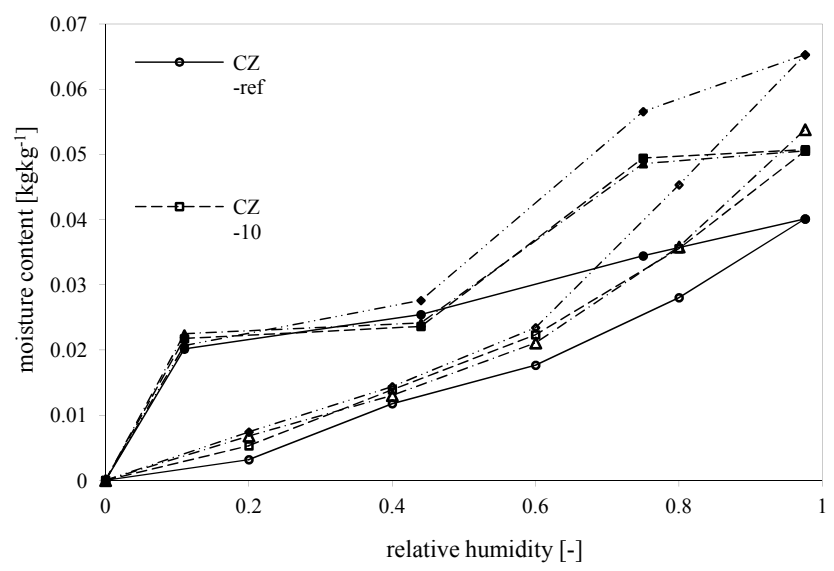

Figure 3: $\quad$ Sorption isotherms of studied concretes.

\subsection{Thermal properties}

The values of thermal conductivity of studied concretes in dry state (Table 7) were in a qualitative agreement with open porosity results (Table 3); the thermal conductivity decreased with the increasing amount of natural zeolites. The values of specific heat capacity decreased with the increasing amount of zeolites. However, the maximum difference was about $5 \%$, as compared with the reference concrete $\mathrm{CZ}$-ref which was within the error range of the measurement method.

Figure 4 shows that the dependence of thermal conductivity of studied materials on moisture content was significant; up to $50 \%$ increase of thermal conductivity was observed for water saturated specimens as compared with the dry state.

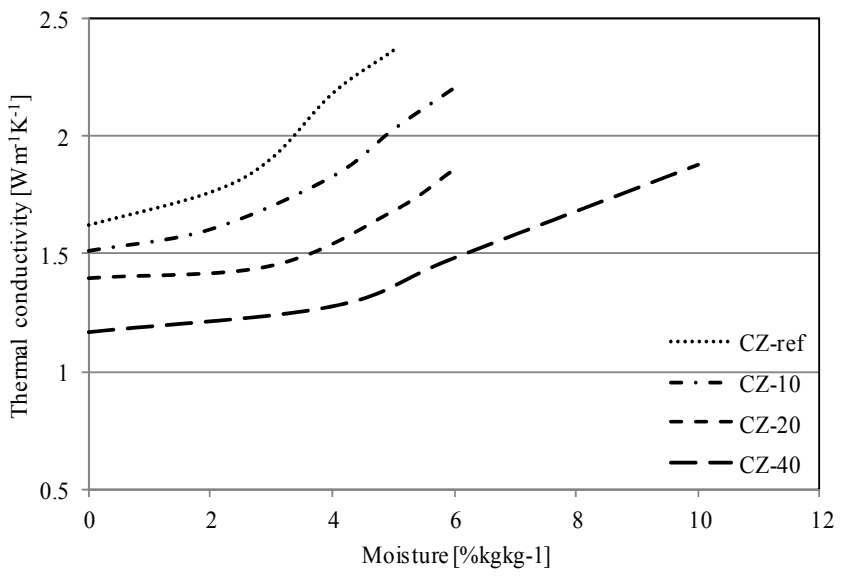

Figure 4: Thermal conductivity of studied concretes. 
The specific heat capacity increased considerably with increasing moisture content (Figure 5) which was related to the high specific heat capacity of water.

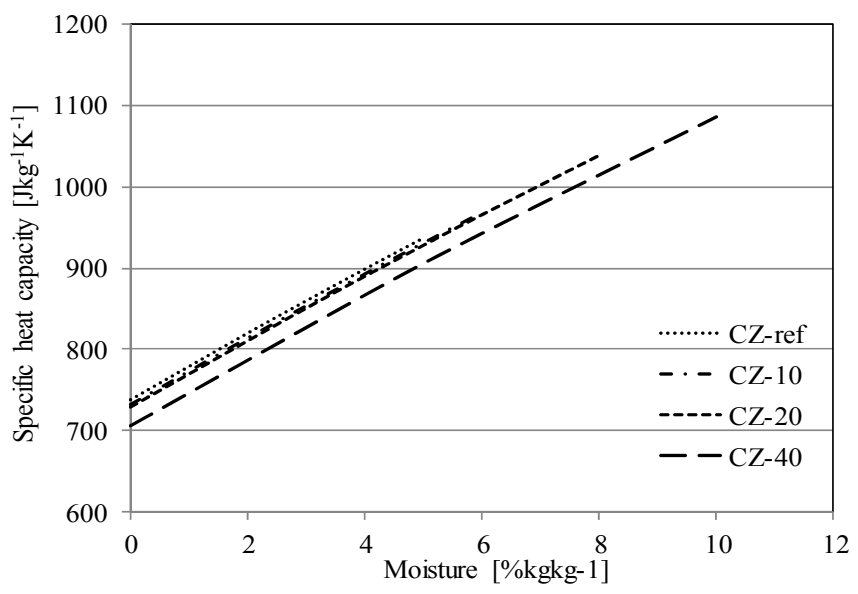

Figure 5: $\quad$ Specific heat capacity of studied concretes.

\section{Conclusions}

Experimental results presented in this paper showed that natural zeolite can be considered an environmental friendly binder with a potential to replace a part of Portland cement in concrete in building industry. However, although it would be desirable from both environmental and economical points of view to use its highest possible amounts in concrete production, the extent of Portland cement replacement which could be chosen in preparation of high performance concrete mixes was found to have relatively strict limitations. The resistance against deicing salts appeared as the main limiting parameter; even the mix with the lowest zeolite content of $10 \%$ did not meet the criteria of the ČSN 731326/Z1:1984 standard. Therefore, this type of concrete should not be used in such cases where de-icing salts are likely to act during its service life. The limitations related to other parameters were not so strict. The mechanical and liquid water transport parameters were satisfactory up to the $20 \%$ replacement level, the water vapor transport parameters, water storage parameters and thermal parameters were acceptable for all studied mixes. Summarizing the above results, it can be concluded that the replacement of Portland cement by natural zeolite in the amount of $20 \%$ by mass can be considered the most suitable option among the studied mixes.

\section{Acknowledgement}

This research has been supported by the Czech Science Foundation, under project No P104/12/0308. 


\section{References}

[1] Stanislao, C., Rispoli, C., Vola, G., Cappelletti, P., Morra, V., De Gennaro, M. Contribution to the knowledge of ancient Roman seawater concretes: Phlegrean pozzolan adopted in the construction of the harbour at Soli-Pompeiopolis (Mersin, Turkey). Periodico di Mineralogia, 80, pp. 471488, 2011.

[2] Su, N., Fang, H.Y., Chen, Z.H., Liu, F.S. Reuse of waste catalysts from petrochemical industries for cement substitution. Cement and Concrete Research, 30, pp. 1773-1783, 2000.

[3] Poon, C.S., Lam, L., Kou, S.C., Lin, Z.S. A study on the hydration rate of natural zeolite blended cement pastes. Construction and Building Materials, 13, pp. 427-432, 1999.

[4] Feng, N., Feng, X., Hae, T., Xing, F. Effect of ultrafine mineral powder on the charge passed of the concrete. Cement and Concrete Research, 32, pp. 623-627, 2002.

[5] Ahmadi, B., Sherkarchi, M. Use of natural zeolite as a supplementary cementitious material. Cement and Concrete Composites, 32, pp. 134-141, 2010.

[6] Janotka, I., Krajci, L. Sulfate resistance and passivation ability of the mortar made from pozzolan cement with zeolite. Journal of Thermal Analysis and Calorimetry, 94, pp. 7-14, 2008.

[7] Bilim, C. Properties of cement mortars containing clinoptilolite as a supplementary cementitious material. Construction and Building Materials, 25, pp. 3175-3180, 2011.

[8] Sisman, C.B., Gezer, E. Performance characteristics of concrete containing natural and artificial pozzolans. Journal and Agriculture and Environment, 9, 493-497, 2011.

[9] Roels, S., Carmeliet, J., Hens, H., Adan, O., Brocken, H., Černý, R., Pavlík, Z., Hall, C., Kumaran, K., Pel, L. and Plagge, R., Interlaboratory Comparison of Hygric Properties of Porous Building Materials. Journal of Thermal Envelope and Building Science, 27, pp. 307-325, 2004.

[10] ČSN EN 12390-3. Testing of hardened concrete - Part 3: Compressive strength. Czech Standardization Institute: Prague, 2002.

[11] ČSN EN 12390-5. Testing of hardened concrete - Part 5: Bending strength. Prague: Czech Standardization Institute, 2007.

[12] ČSN 731326/Z1:1984. Determination of the resistance of the surface of concrete against water and de-icing salts. Prague: Czech Standardization Institute, 2003.

[13] Vejmelková, E., Pavlíková, M., Jerman, M., Černý, R. Free Water Intake as Means of Material Characterization. Journal of Building Physics, 33, pp. 29-44, 2009.

[14] Černý, R., Rovnaníková, P. Transport Processes in Concrete. London: Spon Press, 2002. 